\title{
I mpact of a disinfecting technique on microbial contamination of computer keyboards and telephone handsets
}

\author{
Gabriele Messina ${ }^{1}$, Emma Ceriale ${ }^{2}$, Sandra Burgassi ${ }^{1}$, Carmela Russo ${ }^{2}$, Chiara Defranceschi ${ }^{1}$, \\ Lorenzo Mariani ${ }^{3}$, Lucilla Taddei ${ }^{4}$, Daniele Lenzi ${ }^{5}$, Pietro Manzi ${ }^{5}$ \\ 1. Laboratory of Environmental Hygiene, Department of Molecular and Developmental Medicine, University of Siena, Italy. \\ 2. Postgraduate School of Public Health, University of Siena, Italy. 3. Hospital administration, Rugani Clinic, Siena, Italy. \\ 4. Tuscan Local Health Authority 7, Alta Val D’Elsa Hospital, Siena, Italy. 5. Hospital administration, Teaching Hospital “Le \\ Scotte", Siena, Italy
}

Correspondence: Gabriele Messina. Address: Laboratory of Environmental Hygiene, Department of Molecular and Developmental Medicine, University of Siena, Italy. E-mail: gabriele.messina@unisi.it

Received: March 5, 2013

Accepted: April 8, 2013

Online Published: April 19, 2013

DOI : 10.5430/jha.v2n4p1

URL: http://dx.doi.org/10.5430/jha.v2n4p1

\section{Abstract}

Background: Computers and telephones are ubiquitous in the hospital and have been shown to be contaminated with potentially pathogenic microorganism. The aim of the study was to determine microbial contamination on computer keyboards and telephone handsets and the effectiveness of a disinfecting technique (DT).

Methods: A matched cross-over study, involving an overall of 50 computer keyboards and 50 telephone handsets, was conducted in three hospitals, located in the Local Health Area of Siena (Italy) before and after the use of an innovative DT consisting of a malleable-elastic compound, containing ethanol, which adheres to surfaces, removes dirt and disinfects. Total bacterial count was evaluated and several types of bacteria and fungi were researched pre- and post- use of the DT. Non parametric tests: Wilcoxon signed rank and Mann Whitney, were used, when appropriate.

Results: The DT was effective in disinfecting the objects. In fact, Colony-Forming Units (CFUs) decreased to zero in most comparisons. All the comparisons showed significant differences $(p<0.001)$ after the DT, both for computer keyboards and telephone handsets. The only exception was found for molds in telephones $(p=0.062)$. Keyboards emerged to be dirtier than telephones handsets $(p<0.05)$ for several types of bacteria.

Conclusions: The data suggest that microbial contamination of keyboards and telephones is considerable. These objects can be a vehicle for Health Care-Associated Infections HAIs and their disinfection should not be neglected. The DT showed to be appropriate for the disinfecting purpose.

\section{Key words}

Healthcare-related infection, Computer, Keyboard, Telephone, Hospital, Hygiene, Hospital-acquired infection, Italy

\section{I ntroduction}

Hospital sterilization and environment disinfection practices play a big role in the prevention of health care-associated infections (HAIs). HAIs, also referred to as "nosocomial" or "hospital" infections, are contracted in hospitals or other Published by Sciedu Press 
health care facilities without being present or incubating at the time of admission. They can affect patients in any type of care setting and can also appear after discharge ${ }^{[1]}$. HAIs are the most frequent adverse event in health care ${ }^{[1,2]}$. Hospital infections may be caused by any agent, including bacteria, fungi and viruses, as well as other less common types of pathogens. They represent a significant cause of morbidity and mortality and may increase health care costs ${ }^{[1,2]}$. Several studies have shown contamination of various items of hospital equipment, such as stethoscopes, otoscopes, thermometers, blood pressure cuffs, as well as floors, doors, computer keyboards and telephones (including mobile phones) ${ }^{[2-6]}$. For this study, computers and telephones were analyzed because these objects are actually ubiquitous with an increasing trend in medical settings. Some studies showed that they may act as vehicles to transmit hospital infections ${ }^{[6-8]}$. In fact, in hospital disinfection practices, staff should pay attention not only to medical devices, but also to objects that are not closely related to health activities, such as computers or telephones. The aim of this study was to evaluate contamination of computer keyboards and telephone handsets in three Italian hospitals, before and after the use of a disinfecting technique (DT).

\section{Methods}

A matched cross-over study was conducted in July 2012, involving three hospitals in the Local Health Unit of Siena (Italy). To obtain a real representation of the context, it was decided to research hospitals and units heterogeneity involving: one local public hospital (140 beds), one teaching hospital (750 beds) and a private clinic (40 beds). Moreover we selected the following hospital units: intensive care, operating theatres, emergency units and medical units such as cardiology. In fact common factors associated with nosocomial infections are: admission as an emergency and to intensive care unit (ICU), placement of a central venous catheter, indwelling urinary catheter or an endotracheal tube, undergoing surgery, immunosuppression and coma status ${ }^{[1]}$. Almost all computer keyboards and telephones used by healthcare staff, in these units were analyzed. The final sample was 50 computer keyboards and 50 telephone handsets

The DT consists of an innovative putty compound with malleable-elastic consistency, designed to adhere to surfaces, removing dirt and disinfecting. These two characteristics distinguish this DT from traditional methods of cleaning and disinfection. Moreover its structure can penetrate into spaces between and under keys. The main sanitizing principle was ethanol (29\%), and in addition the compound contained purified water (51\%), guar (6\%), glycerine (7\%), and a minor quantity of other substances such as boric acid, colorants and odorants.

The experimental protocol required a first sample (swab) $\mathrm{H}(0)$ from one half of each keyboard or telephone before cleaning, and a second sample $\mathrm{H}(1)$ from the other half after cleaning. Because the two halves of the keyboard are different and some keys are used more than others (for example "enter") we alternated the side to which the DT was applied. Taking samples from both halves of the keyboards or handsets was important to avoid the possibility that the first swabs removed bacteria physically, reducing the amount of bacteria collected by the second swab from the same surface and preventing correct assessment of DT efficacy in reducing bacterial contamination. Samples were obtained by swabbing almost all the keys and also going between/under the keys with cotton sterile pads. It took approximately 20-30 seconds for each keyboard and 15-20 seconds for each telephone sample. The cleaning process lasted approximately 20-30 seconds for telephones and 2-4 minutes for keyboards, depending on dirtiness. Cleaning was continued until: i) the half keyboard or handset looked clean; ii) there was no visible grime on the keys or handset; iii) no further improvement was visibly detectable. Once sample H(1) was obtained, the other previously swabbed half of the keyboard or handset $H(0)$ was cleaned to leave it in acceptable condition. A new pack of compound was used for each object. Each object was assigned an identification number.

In the laboratory, the swabs were placed in $1 \mathrm{ml}$ of phosphate buffered saline, shaken in a vortex mixer for 20 seconds and the liquid sown ( $0.1 \mathrm{~mL} /$ plate) in Petri dishes containing plate count agar (PCA) for total microbial load incubating at $36^{\circ} \mathrm{C}$ for bacteria colonizing humans, $22^{\circ} \mathrm{C}$, for environmental bacteria. In addition we used: mannitol salt agar for Staphylococcus spp., Pseudomonas cetrimide for Pseudomonas spp., Slanetz \& Bartley medium for Enterococcus spp., Brilliance E. coli/Coliform spp. chromogenic medium for Escherichia coli and coliform bacteria, Acinetobacter base for 
Acinetobacter spp, and Brilliance methicillin-resistant Staphylococcus aureus (MRSA) MRSA2 medium for methicillinresistant Staphylococcus aureus, incubating at $36^{\circ} \mathrm{C}$. The results were expressed as colony-forming units (CFUs) per swab. The plates were read 24 and 48 hours after sowing.

Descriptive analysis (mean, standard deviation, median, interquartile range, minimum, maximum) of the data for all types of microbes/molds was performed for $\mathrm{H}(0)$ and $\mathrm{H}(1)$. To reveal differences in bacterial contamination before and after use of the DT and to comparate the level of dirtiness/contamination between telephone handsets and keyboards, before use of DT, non-parametric tests: Wilcoxon signed rank and Mann Whitney, were used, when appropriate. Significance level was set $p<0.05$. Stata ${ }^{\circledR}$ SE, version 12.1, StataCorp, College Station, Texas, USA, software was used for the analysis.

Table 1. Descriptive statistics of computer keyboards and telephone handsets at $\mathrm{H}(0)$ and $\mathrm{H}(1)$ : Number and percentage of positive samples, overall CFUs counts and percentage reduction in CFUs from $\mathrm{H}(0)$ to $\mathrm{H}(1)$, means, standard deviations, medians, interquartile ranges, minima and maxima

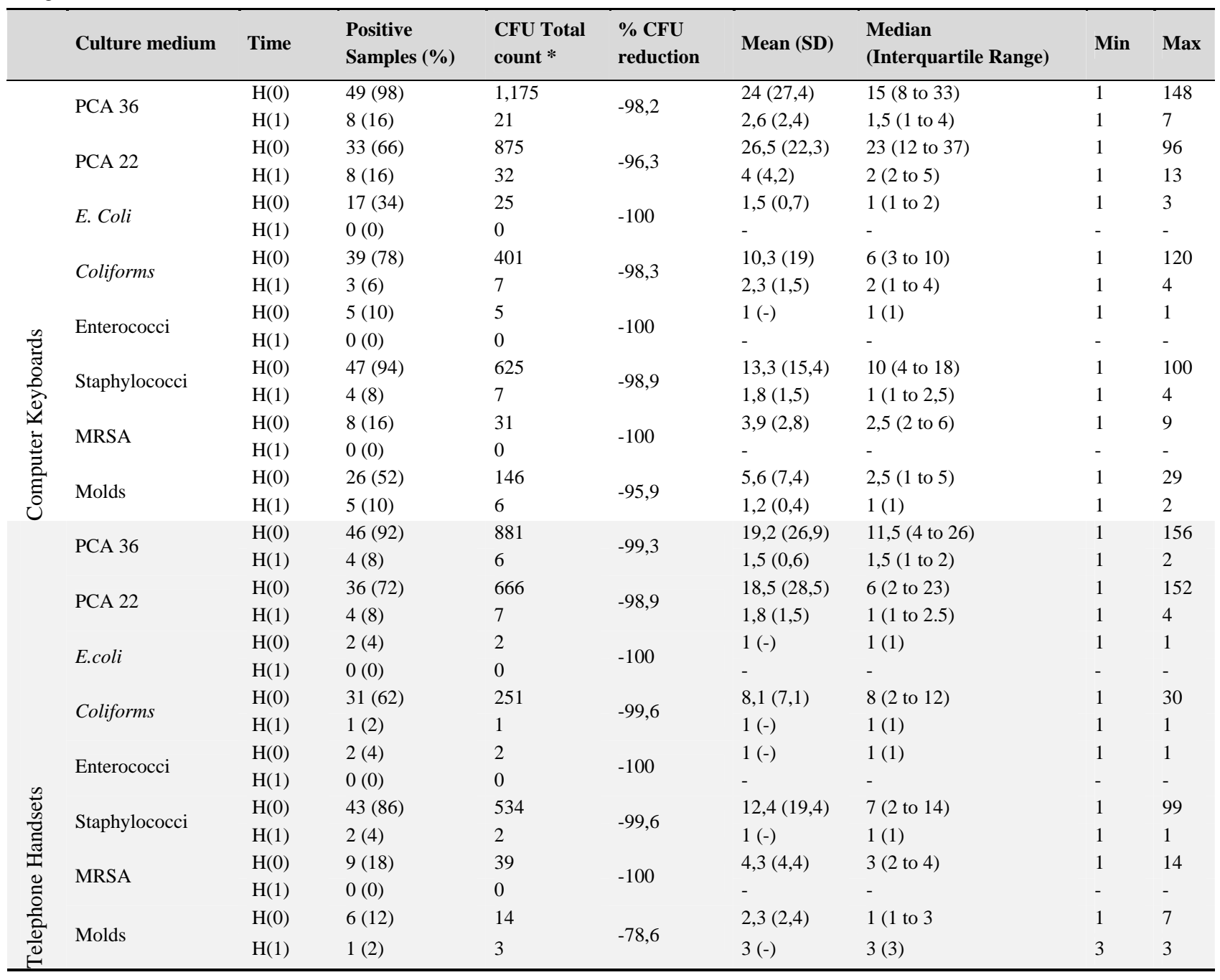

* Summing all CFUs on the computer keyboards and telephone handsets; Only positive samples

\section{Results}

Descriptive results are summarized in Table 1. No samples contained Pseudomonas spp. CFUs decreased to zero in most comparisons. In cases where the number of CFUs in H(1) did not correspond to 0 , statistical tests were carried to highlight 
whether the differences between pre- and post- cleaning was significant. All the comparisons showed significant differences $(p<0.001)$ after the DT, both for computer keyboards and telephone handsets. The only exception was found for molds in telephones $\left(p=0.062\right.$ ). For PCA $36^{\circ} \mathrm{C}, \mathrm{H}(0)$ samples of $49 / 50$ keyboards and 36/50 telephones were contaminated, whereas $\mathrm{H}(1)$ samples of only 8 keyboards and 4 telephones were still contaminated. For PCA $22^{\circ} \mathrm{C}, 33 / 50$ keyboards and 36/50 telephones were contaminated before cleaning and 8 and 4 were still positive, respectively, after cleaning. For coliforms 39/50 keyboards and 31/50 telephones were contaminated before cleaning and 3 keyboards and 1 telephone were still contaminated after cleaning. Some Escherichia coli and Enterococcus spp. were detected on keyboards and telephones before cleaning but none after cleaning. Staphylococcus spp. was detected on keyboards (47/50) and telephones (43/50) before cleaning and almost none after cleaning. Some Staphylococcus spp. were MRSA but were absent after cleaning. Only 1 CFU of Acinetobacter spp. was detected on one out of 50 computer keyboards before cleaning but the keyboard was negative after cleaning. Finally, for molds 26/50 keyboards and 6/50 telephones were contaminated before cleaning, whereas after cleaning only 5/26 keyboards and 1/6 telephones were positive. At a glance keyboards looked much dirtier than telephones (Figure 1), moreover they were more contaminated at $\mathrm{H}(0)$ for: PCA 36 ( $p=0.028)$, E.coli $(p=0.001)$, Staphylococcus spp. $(p=0.038)$ and molds $(p<0.001)$.

Figure 1. Example of keyboard during cleaning with the DT

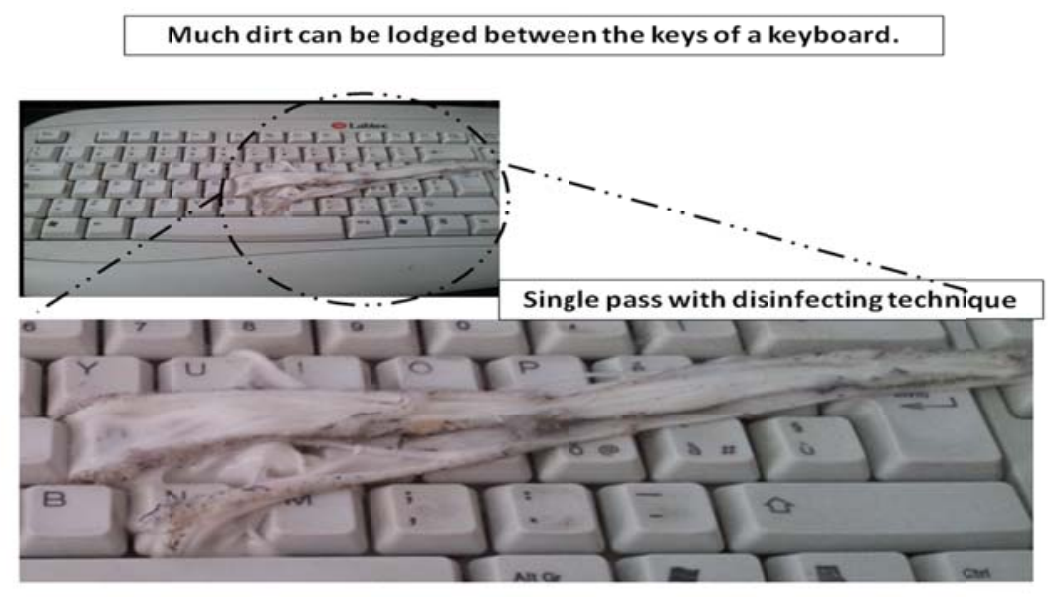

\section{Discussion}

In recent years the number of computers and telephones in hospitals has increased. Care-givers frequently touch keyboards and/or telephone handsets, immediately after/before patient-related procedures without performing hand hygiene. This habit increases the risk of patient contamination/infection ${ }^{[7]}$. Simple measures, some of which are already in use, such as installation of antibacterial hand gel dispensers in hospital units, could make hand cleaning procedures easier. Some studies, have investigated microbial contamination of computers and telephones and their role in the transmission of health-care-associated infections ${ }^{[8]}$. Some of these infections are very dangerous, for example in Europe; MRSA is frequently isolated in Italian, Spanish, Greek, Portuguese and British hospitals ${ }^{[2,9]}$.

In line with the results of this study, other studies reported that the bacteria most commonly isolated were gram-positive cocci, especially Staphylococcus spp ${ }^{[2,10,11]}$. In fact, 47/50 computer keyboards and 43/40 telephone handsets were positive for these bacteria. Between these 8/50 and 9/50 were positive for MRSA, respectively. Also isolated were several bacterial species associated frequently with nosocomial transmission, such as coliforms and enterococci ${ }^{[12]}$. In addition, one computer keyboard was also contaminated with Acinetobacter Spp. an emerging bacteria in HAIs ${ }^{[13]}$.

The prevention of HAIs also has importance for the financial burden on health care costs. In Europe HAIs causes 16 million extra-days of hospital stay and an annual economic impact estimated at approximately €7 billion, including only 
direct costs ${ }^{[1]}$. Several studies have also investigated the effectiveness of liquid products to disinfect computer keyboards ${ }^{[2,7]}$. Advances in this field include computer keyboards without spaces between the keys, with their surface being completely sealed, and those made of special materials, such as washable keyboards that can be immersed in water ${ }^{[13,14]}$. Touch screen computer keyboards and telephone handsets are easy to clean. Although these new keyboards and handsets could be used in new health environments, it is difficult to quickly replace devices already in use. Liquid compounds, such as ethyl alcohol, may cause aesthetic and functional damage ${ }^{[2,7]}$, such as short circuiting keyboards. The DT tested in this study did not leave computer keyboards and telephone handsets wet. It had the advantage of disinfecting, mainly by virtue of its ethanol content, and, at the same time of cleaning, mechanically removing dirt and grime through adhesion. Its structure can penetrate into spaces between and under keys.

This study's main limitation is the small sample size if compared to the overall numbers of keyboards and telephone handsets which were in the hospitals. Included were almost all of these objects in the units with a high risk of HAIs. Another limit was the impossibility to extend the effectiveness of the DT to those bacteria which were not found, for example Pseudomonas spp, or not researched.

It remains important to sensitize health professionals to sanitize devices directly or indirectly involved in patient care, such as keyboards and telephone handsets. The latter are a potential source of infection as their cleanliness is often neglected. The results suggest that the DT tested could be a good compromise in contexts where the above technological innovations cannot be implemented immediately.

\section{Acknowledgements}

We thank the hospital administrations of Siena Teaching Hospital “Le Scotte”, Rugani Clinic, Siena, and Alta Val D'Elsa Hospital. The study was conducted under the Master Research and Service Agreement (D.R. 341/2012 signed 6/3/2012, Exhibit 2 and 3 signed 9th July 2012) between the University of Siena and Joker AG/SA. Joker AG/SA financed the research.

\section{Permission to use the data}

Use of the data was authorized by the three hospital administrations.

\section{Conflict of interests}

The authors declare that they have no conflict of interests.

\section{References}

[1] WHO, Report on the Burden of Endemic Health Care-Associated Infection Worldwide. 2011; 1-34.

[2] Rutala, W.A., et al., Bacterial contamination of keyboards: efficacy and functional impact of disinfectants. Infect Control Hosp Epidemiol, 2006; 27(4): 372-7. PMid:16622815 http://dx.doi.org/10.1086/503340

[3] Messina, G., et al., Indagine sulla contaminazione microbica di stetoscopi, telefoni e tastiere di computer presso una casa di cura. Mondo Sanitario, 2012; XIX(10): 1-5.

[4] Messina, G., et al., How many bacteria live on the keyboard of your computer? Am J Infect Control. 2011; 39(7): 616-8. PMid:21782282 http://dx.doi.org/10.1016/j.ajic.2010.12.023

[5] Ng, L.S., et al., Bacterial contamination of hands and the environment in a microbiology laboratory. J Hosp Infect. 2011; 78(3): 231-3. PMid:21481970 http://dx.doi.org/10.1016/j.jhin.2011.01.025

[6] Schultz, M., et al., Bacterial contamination of computer keyboards in a teaching hospital. Infect Control Hosp Epidemiol. 2003; 24(4): 302-3. PMid:12725363 http://dx.doi.org/10.1086/502200

[7] Wilson, A.P., et al., Computer keyboards and the spread of MRSA. J Hosp Infect. 2006; 62(3): 390-2. PMid:16337027 http://dx.doi.org/10.1016/j.jhin.2005.09.007

[8] Singh, V., et al., Telephone mouthpiece as a possible source of hospital infection. J Assoc Physicians India. 1998; 46(4): 372-3. PMid:11273321 
[9] European Centre for Disease Prevention and Control, EARSS Annual Reports, 2010.

[10] Brady, R.R., et al., Mobile phone technology and hospitalized patients: a cross-sectional surveillance study of bacterial colonization, and patient opinions and behaviours. Clin Microbiol Infect. 2011; 17(6): 830-5. PMid:21615607 http://dx.doi.org/10.1111/j.1469-0691.2011.03493.x

[11] Lu, P.L., et al., Methicillin-resistant Staphylococcus aureus and Acinetobacter baumannii on computer interface surfaces of hospital wards and association with clinical isolates. BMC Infect Dis. 2009; 9: 164. PMid:19796381 http://dx.doi.org/10.1186/1471-2334-9-164

[12] Zarb, P., et al., The European Centre for Disease Prevention and Control (ECDC) pilot point prevalence survey of healthcare-associated infections and antimicrobial use. Euro Surveill. 2012; 17(46). PMid:23171822

[13] Neely, A.N., et al., Computer equipment used in patient care within a multihospital system: recommendations for cleaning and disinfection. Am J Infect Control. 2005; 33(4): 233-7. PMid:15877019 http://dx.doi.org/10.1016/j.ajic.2005.03.002

[14] Reuters. Unotron washable keyboards, mice help schools prevent virus outbreaks, meet CDC recommendations. 2008 [Internet]. Available from: http://www.reuters.com/article/2008/01/10/idUS170771+10-Jan-2008+BW20080110 (9 april 2013). 